\title{
Renewable energy as a factor of sustainable development and regulation of ecological problems in Africa
}

\author{
Liudmila Nefedova ${ }^{1, *}$, Alexander Solovyev ${ }^{1}$, Yulie Rafikova ${ }^{1}$, Dmitriy Solovyev ${ }^{2}$ \\ ${ }^{1}$ Lomonosov Moscow State University, 119991 Leninskie gory, 1/19, GSP-1 Moscow, Russian \\ Federation \\ ${ }^{2}$ Shirshov Institute of Oceanology, Russian Academy of Sciences, 117997, Nakhimovsky Prospect, \\ 36, Moscow, Russian Federation
}

\begin{abstract}
The analysis of the main directions of renewable energy in Africa, as a factor in sustainable development and reduction of greenhouse gas emissions is performed. The ecological problems of the modern and prospective development of the energy complex of African countries are considered. For African countries the issue of ensuring reliable and environmentally friendly access to electricity for the population is extremely acute. It is shown, that the electricity demand for industry in Sub-Saharan Africa - the most problematic region - is growing on a very large scale. The construction of new large coal-fired thermal power plants in the required volumes will lead to serious environmental and climatic consequences. The study of regional data allowed us to conclude that PV solar systems are of priority importance for increasing people's access to electricity in rural SubSaharan Africa. Based on numerous materials from international energy structures the estimates and calculations of volumes of reduction of greenhouse gas emissions due to the use of renewable energy sources as an alternative to carbon fuel are carried out. The study has shown that of particularly great importance for reducing $\mathrm{CO}_{2}$ emissions in Kenya is the development of geothermal energy.
\end{abstract}

\section{Introduction}

The carbon-free path of energy development in Africa is an important contribution to solving such problems of global warming, greenhouse gas emissions, forest destruction. The problem of access to electricity is one of the priority conditions for the economic and social development of African countries. In African countries with high potential resources of renewable energy, development of renewable energy resources is an important factor of social and economic development of these countries, increase of energy and economic independence, as well as a lever to overcome the spatial heterogeneity of the population's access to electricity, improve ecological conditions and fight against deforestation. The problem of low electricity access for people in rural Africa is one of the most acute problems

\footnotetext{
* Corresponding author: nefludmila@mail.ru
} 
of our time. About 600 million rural people do not have access to grid electricity, of which $98 \%$ are concentrated in the Sub-Saharan region. Access to electricity is extremely low: as of 2018 - on average in Sub-Saharan Africa (SSA) - 43\%. In 30 countries, the indicator is from $11 \%$ to $39 \%$, and in 10 countries - less than $10 \%$ [1].

Without electricity, it is challenging, if not impossible, to promote economic growth, overcome poverty, expand employment, and support human development. Sustainable energy is the seventh goal of the $17 \mathrm{UN}$ Sustainable Development Goals (SDGs), with a call to "ensure access to affordable, reliable, sustainable and modern energy for all." Its five targets indicate areas where policies can be designed-such as boosting the share of renewable energy (RE) in the global energy mix and doubling the global rate of improvement in energy efficiency [2]. Most of the countries in the region plan to increase 3-5 times the installed capacity of power plants and the generation of electricity by 2030 to overcome the shortage of electricity and increase public access to electricity [1]. Such a scale of building up the electricity generating capacities required for the economic development of the region when using carbon fuel will have tremendous environmental and climatic consequences.

\section{Object of study and methods}

The objective of the study was to assess the significances of using renewable energy sources to ensure sustainable development of the region. The authors consider renewable energy in African countries in terms of its importance for providing increased access to electricity for the population, reducing carbon dioxide emissions from electricity generation and the problem of use of wood as a fuel for cooking, which leads to a decrease the forest areas on the continent.

The present article consists of an analytical review of the literature, statistical calculations, and expert estimates. As a research tool, we used analysis and synthesis methods, a statistical research method, as well as tabular methods for presenting research results. The research information base was compiled from official data of the International Renewable Energy Agency, the International Energy Agency, of the World Bank and for international ecological organizations, as well as the official websites of African countries Energy Organizations.

\section{Results and Discussion}

\subsection{Ensure universal electricity access}

The population of Africa have different possibility in access to electricity. In North African countries this index is $95-100 \%$ (tab.1). For East and Central Africa the issue of ensuring reliable and environmentally friendly access to electricity for the population is extremely acute. The use of diesel generators is not always effective, since the burning of liquid fuel has a negative impact on the environment, depends on the reliability of fuel supplies, especially taking into account factors such as imperfect transport infrastructure and the risk of fuel theft. Africa's demand for electricity and for industrial development is growing on a very large scale. The total capacity of power plants on the continent over 20 years has more than doubled [2]. The construction of new large coal-fired thermal power plants in the required volumes will lead to serious environmental and climatic consequences. In Africa the number of people gaining access to electricity doubled from 9 million a year between 2000 and 2013 to 20 million people between 2014 and 2018, outpacing population growth. As a result, the number of people without access to electricity, which peaked at 610 million in 2013, declined slowly to around 595 million in 2018. Much of this recent dynamism has 
been in East Africa, as Kenya, Ethiopia and Tanzania accounted for more than $50 \%$ of those gaining access.

Table 1. Population access to electricity in Africa regions [3].

\begin{tabular}{|c|c|c|c|}
\hline & $\begin{array}{c}\text { Population, } \\
\mathrm{mln}\end{array}$ & $\begin{array}{c}\text { Percent of } \\
\text { Population access to } \\
\text { electricity }\end{array}$ & $\begin{array}{c}\text { Average annual } \\
\text { electricity consumption } \\
\mathrm{kWh} / \mathrm{pp}\end{array}$ \\
\hline North Africa & 175 & $98 \%$ & 1574 \\
\hline West Africa & 327 & $47 \%$ & 188 \\
\hline East Africa & 303 & $23 \%$ & 91 \\
\hline Central Africa & 115 & $25 \%$ & 167 \\
\hline South Africa & 177 & $93 \%$ & 2061 \\
\hline
\end{tabular}

The access rate to electricity rose in Kenya from $25 \%$ in 2013 to $75 \%$ in 2018 due to RES development. The study of regional data allowed us to conclude that solar PV systems are of priority importance for increasing people's access to electricity in rural Africa. In rural and remote regions improved access to energy can generally be acquired in three ways:

1) grid-based centralized electrification, where the grid is extended beyond urban and peri-urban areas.

2) community-level or renewable energy-based mini- or micro-grid systems;

3 ) household-level use of isolated devices and stand-alone systems to generate power lighting and heat for space and water heating, cooking and productive uses.

For off-grid power supply of autonomous consumers, the most cost-effective is the creation of local mini-grids with photovoltaic installations in several settlements or agricultural facilities. New forms of financing are used, for example, Pay \& Go for standalone installations, auctions for large facilities on renewable energy sources [4]. The majority of progress over the past decade in Africa has been made as a result of grid connections, but a rapid rise has been seen in population access to electricity via solar home systems. Kenya, Tanzania and Ethiopia accounted for around half of the 5 million people gaining access through new solar home systems according to latest estimations in 2018 (up from only 2 million in 2016) [1]. The levelized cost of electricity (LCOE) in the rural mini grids in Kenya and Tanzania analyzed in this study ranged from $\$ 0.55$ to $\$ 0.85$ per $\mathrm{kWh}$, with a median cost of $\$ 0.66$, using a $22 \%$ load factor. Development partners and governments will need to crowd in private-sector investment and enabling mini grid business environments in key accessdeficit countries. These combined efforts can bring down the cost of mini grid electricity to $\$ 0.25 / \mathrm{kWh}$ by 2025 and $\$ 0.20 / \mathrm{kWh}$ by 2030 [5].

To the 2019 the total installed capacity RE power plants in Africa countries was of 14.6 GW, including: wind farms - $5765 \mathrm{MW}$, solar power plants (PP) - $6367 \mathrm{MW}$, bioelectric PP - $1713 \mathrm{MW}$, geothermal PP - $830 \mathrm{MW}$ [1]. The leader of wind energy in Sub-Saharan Africa is Ethiopia: three large wind farms - Adama I \&II (205 MW), Ashegoda (120 MW). In Kenya - Lake Turkana Windfarm (310 MW). Geothermal resources are concentrated in the zone of the East-African Valley with the length of $6000 \mathrm{~km}$ (estimated $20000 \mathrm{MW}$ ) in the territories of Eritrea, Djibouti, Ethiopia, Kenya, Uganda, Rwanda, Tanzania, Zambia. The greatest success in geothermal energy was achieved by Kenya, the total installed capacity of Geothermal Power Plants (813 MW). The region has the Carbon Assets Development Fund for Africa (ACAD), a public-private partnership sponsored by UNEP. ACAD serves as a platform to stimulate investment, provides seed funding and advises green entrepreneurs on carbon credits and investing in low-carbon energy initiatives.

\subsection{Biomass in energy balance and problem of deforestation}

The energy balance of the countries of the region is dominated by plant and animal biomass for cooking, electricity on average is less than $10 \%$. This leads to a process of catastrophic 
deforestation. Mass deforestation is one of the most important environmental problems of our time. Forest communities play a crucial role in the normal functioning of natural ecosystems. They absorb atmospheric pollution of anthropogenic origin, protect the soil from erosion, regulate the normal runoff of surface water, prevent the decrease in groundwater levels and siltation of rivers, canals and reservoirs. The decrease in forest area disrupts the cycle of oxygen and carbon in the biosphere. Despite the fact that the catastrophic consequences of deforestation are already widely known, their destruction continues. Energy from biomass accounts for more than $30 \%$ of the energy consumed in Africa and more than $80 \%$ in many sub-Saharan African countries. Indoor pollution from biomass cooking - a task usually carried out by women - will soon kill more people than malaria and HIV/AIDS combined [6]. If measures will not to be taken to change the structure of consumption of energy sources, then the population growth in the region will lead to the situation that the consumption of energy raw materials from biomass, in particular wood fuel, will increase by $40 \%$ by 2040 and will cause a significant reduction of forest areas. In Sub-Saharan Africa traditional biomass burning supplies more than $92 \%$ of national energy consumption. In the region, such biomass resource as wood, agro-industrial residues and municipal waste are available is expected to meet the countries growing energy demand and can provide huge opportunity for the adoption of the briquetting technology. In some African countries, in the Republic of the Congo, for example, biomass briquettes are sold as an alternative to charcoal to protect Virunga National Park from deforestation associated with charcoal production.

The Africa Biogas Partnership Program (ABPP) in Kenya, Tanzania and Uganda was established in 2009 to promote adoption of biodigesters by rural households in sub-Saharan region. Between 2009 and 2017 over 27,000 households installed a biodigester, half of them in Kenya. Additional objectives include improving agricultural productivity by using bioslurry, improving health, reducing deforestation, and improving livelihoods. Households perceive higher crop yields ( $84 \%-91 \%$ of users), reduced fuel consumption $(84 \%-94 \%$ of users), reduced eye problems and respiratory symptoms (45\%-91\% of users). Benefits most appreciated are "easy cooking" and "saving time and money". Fuel consumption tests show households with biodigesters use 2.1 to 3.3 fewer tons of wood per year than similar households without biodigesters [7].

\subsection{Carbon dioxide emission}

In recent years, the increase in $\mathrm{CO}_{2}$ emissions by African countries has been extremely rapid and reached by 2018 more than 1.3 bln tons per year. Since 1990 greenhouse gas emissions increased in the region by $42 \%$ (in Ethiopia - by $85 \%$, in Kenya - by $62 \%$ ) [8]. The use of diesel generators is not always effective, since the burning of liquid fuel has a negative impact on the environment. The cost of generator proliferation is an exceptionally high level of $\mathrm{CO}_{2}$ emissions. While a coal power plant, usually considered the worst energy option for the environment, might produce $\sim 1000 \mathrm{~g} \mathrm{CO}_{2} / \mathrm{kWh}$, an individually-owned $5 \mathrm{~kW}$ diesel generator emits twice as much. In Nigeria, which is Africa's largest importer of diesel generators with an estimated $9 \mathrm{mln}$ units in use, generators produce about 29 million metric tons of $\mathrm{CO}_{2}$ each year [9]. Our analysis of African countries' sources showed that the largest government programs for the use of renewable energy in Sub-Saharan Africa (except South Africa, which implements its own large-scale programs for the development of renewable energy sources), have been launched in recent years in Ethiopia and Kenya. In this study, we collected information about operating power plants and potential projects of renewable energy facilities in Kenya, a leader on the use of geothermal resources on the African continent. The construction of geothermal power plants (GeoPP) in Kenya with the injection of condensation water back into the reservoir and the practical absence of a soil layer in the drilling zones reduces their environmental impact on the surrounding territory. Based on the collected materials on the location and operation of power plants, estimates of the installed capacity 
utilization factor (ICUF) were performed. Using the values of this coefficient, estimates and calculations of the average annual volume of electricity generation at the scheduled power plants were carried out. The further calculations allowed the authors to estimate the volume of $\mathrm{CO}_{2}$ emission reduction due to the rejection of the use of carbon fuel at these power plants (tab.2). As can be seen from the table 2, the Ministry of Energy and Petroleum of Kenya plans to bring the capacity of RE power plants to $4400 \mathrm{MW}$, and we have calculated that this will allow the country to avoid 13 million $\mathrm{tCO}_{2}$ emissions per annum in the energy sector. The GeoPP will make the largest contribution in this output of more than 10 million tCO2/ year, since the ICUF is much higher than that of wind and solar power plants.

Table 2. $\mathrm{CO}_{2}$ emission reducing due to sustainable power generation in operating RE Power Plants in 2019 and scheduled Projects in Kenya

\begin{tabular}{|c|c|c|c|c|}
\hline Name of RE Power Plants & $\begin{array}{l}\text { Installed } \\
\text { capacity }\end{array}$ & $\begin{array}{c}\text { Commised / } \\
\text { Planned }\end{array}$ & $\begin{array}{c}\text { Power } \\
\text { generation } \\
(\text { GWh/yr) }\end{array}$ & $\begin{array}{l}\mathrm{CO}_{2} \text { emission } \\
\text { reducing }(\mathrm{Kt})\end{array}$ \\
\hline Olkaria I \& II GeoPP & $290 \mathrm{MW}$ & $1981-2014$ & 2032.3 & 1829.1 \\
\hline Olkaria III & $139 \mathrm{MW}$ & $2008-2017$ & 974.5 & 877.1 \\
\hline Olkaria IV & $140 \mathrm{MW}$ & 2014 & 981.1 & 883.0 \\
\hline Olkaria V & $172 \mathrm{MV}$ & 2019 & 1205.4 & 1084.9 \\
\hline Eburru GeoPP & $2,4 \mathrm{MW}$ & 2017 & 16.8 & 15.2 \\
\hline Well head Generation & $70 \mathrm{MW}$ & 2018 & 490.6 & 441.5 \\
\hline Total GeoPP & 813.4 MW & & 5700.7 & 5130.9 \\
\hline Ngong Hills Wind Power & $25.5 \mathrm{MW}$ & $1993-2014$ & 60.3 & 157.0 \\
\hline Lake Turkana Windfarm & $310 \mathrm{MW}$ & 2018 & 701.7 & 203.5 \\
\hline Solar Plant Garisssa & $50 \mathrm{MW}$ & 2019 & 68.7 & 10.3 \\
\hline Total operating RE PP & 1188.9 & & 6531.4 & 5501.7 \\
\hline \multicolumn{5}{|l|}{ Scheduled Projects } \\
\hline Olkaria VI Geo Project & $140 \mathrm{MW}$ & 2025 & 980 & 882.0 \\
\hline Menengai Geo Project & 400MW & 2030 & 2800 & 2380.0 \\
\hline Baringo-Silali Geo Project & $300 \mathrm{MW}$ & 2028 & 2100 & 1890.0 \\
\hline Suswa Geo Project & $300 \mathrm{MW}$ & 2026 & 2100 & 1890.0 \\
\hline Lamu Electrawinds & $90 \mathrm{MW}$ & 2022 & 220 & 61.6 \\
\hline Isiolo Wind Power & $150 \mathrm{MW}$ & 2025 & 368 & 103.0 \\
\hline Kipeto Wind Project & $100 \mathrm{MW}$ & 2023 & 236 & 63.7 \\
\hline Meru Wind Power & $400 \mathrm{MW}$ & 2030 & 876 & 245.3 \\
\hline Solar PV Plant Seven forks & 40MW & 2021 & 52,5 & 7.9 \\
\hline New Solar Projects & $400 \mathrm{MW}$ & 2030 & 525 & 89.3 \\
\hline Total scheduled Projects & $3220 \mathrm{MW}$ & & 10257.5 & 7612.8 \\
\hline
\end{tabular}

Source: completed by the authors based on [10], [11], [12].

Solar mini grids as an alternative to diesel generators will have also a significant positive environmental impact in carbon dioxide emission reducing. It was estimated that by 2030 , mini grids of 10-15 GW of PV stations in Sub-Saharan Africa will avoid 22-35 million $\mathrm{tCO}_{2} /$ year emissions. 


\section{Conclusion}

Africa is one of the most problematic regions in terms of the widespread use of biomass burning for cooking and heating, leading to the reduction of forests, extremely low access of the population to electricity, as well as underdeveloped infrastructure and power lines. The countries of Africa, including those located to the south of the Sahara, have a very high potential for renewable energy sources RES. The main factor for its development is electricity deficit and extremely low access of the population to electricity, development of these resources is necessary for sustainable social and economic development of the region. The development and strengthening of the concept of sustainable development contributes to the increase of renewable energy sources role in the energy sector. A number of countries in the region introduced government measures to support the development of electricity for RES, drawn up plans for their use and carried out rural electrification programs. The process of developing renewable energy sources in the region is possible only with the support of international environmental and financial structures, which are already participating actively in this issue. Many countries in Africa have already begun the process of developing RES, receiving support from international structures in this process. It is planned to provide total access to electricity by the year 2030 at the initiative of the UN in the region, using RES at the same time. The RES development is one of the main factors to solve the problems of forest reduction and carbon dioxide emission in Africa. The government plans of Kenya plans to bring the capacity of RE power plants to $4400 \mathrm{MW}$ to 2030 will allow the country to avoid 13 million $\mathrm{t} \mathrm{CO}_{2}$ emissions per annum in the energy sector. The GeoPP will make the largest contribution in this output of more than 10 million $\mathrm{t} \mathrm{CO}_{2} /$ year. Solar mini grids as an alternative to diesel generators of $10-15 \mathrm{GW}$ of PV stations in Sub-Saharan Africa will to

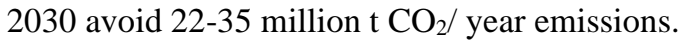

The study was carried out within State Assign AAAA-A16-116032810088-8 and 0149-2020-0003.

\section{References}

1. Africa Energy Outlook: World Energy Outlook Special Report (IEA, Paris, 2019)

2. Africa Sustainable Development Report: Tracking Progress on Agenda 2063 and the Sustainable Development Goals. African Union (AfDB and UNDP, Addis Ababa, 2017)

3. Renewables 2019. Global status report UNEP (REN21 Secretariat, Paris, 2019)

4. L.V.Nefedova, A.A.Solovyev et al., IGI Global in Engineering, 154-168, (Hershey, 2019)

5. Electricity storage and renewables: costs and markets to 2030 (IRENA, 2017)

6. L. Tusting, D. Bisanzio, G. Alabaster et al., Nature, 568, 391-394 (2019)

7. H. Clemens, R. Bailis, A. Nyambane et al. Energy for Sust. Dev, 46, 23-31 (2018)

8. S.A. Asongu Environ Sci Pollut Res, 25, 9351-9359, (2018)

9. Mini Grids for Half a Billion People: Market Outlook and Handbook for Decision Makers. ESMAP Technical Report, World Bank (Washington, 2019).

10. Renewable energy statistics 2019 (IRENA, 2019)

11. Kenya Electricity Generating Company PLC (KenGen). URL: https://kengen.co.ke/index.php/business/projects/ongoing.html

12. "The Geothermal Development Company» Kenya. URL: http://www.gdc.co.ke 